\title{
JNPH
}

Volume 6 No. 1 (April 2018)

(C) The Author(s) 2018

\section{ANALISIS FAKTOR YANG BERHUBUNGAN DENGAN MEKANISME KOPING PASIEN HEMODIALISA RSUD DR. M. YUNUS BENGKULU}

\author{
ANALYSIS OF FACTORS RELATED TO COPING MECHANISMS ON \\ HEMODIALYSIS PATIENTS OF DR. M. YUNUS HOSPITAL BENGKULU
}

\author{
HANDI RUSTANDI, HENGKY TRANADO, DAN HELEN XLARA DARNALIA \\ FAKULTAS ILMU KESEHATAN DEHASEN \\ Email : handi_rustandi@ymail.com
}

\begin{abstract}
ABSTRAK
Penyakit gagal ginjal kronik (GGK) adalah keadaan klinis kerusakan ginjal yang progresif dan ariableble yang berasal dari berbagai penyebab penyakit. Dari data di beberapa pusat nefrologi di Indonesia diperkirakan insidens dan prevalensi penyakit ginjal kronik masing-masing berkisar 100-150/1 juta penduduk dan 200-250/1 juta penduduk, Namunyang terdeteksi menderita Gagal Ginjal Kronik yang menjalani cuci darah(Hemodialisa) hanya sekitar 4000 sampai 5000 saja.Untuk itu penelitian ini bertujuan mengetahui faktor-faktor dominan yang berhubungan dengan mekanisme koping pasien hemodialisa diruang hemodialisa RSUD Dr. M. Yunus Bengkulu Tahun 2016. Jenis penelitian yang digunakan dalam penelitian ini adalah penelitian secara Analitik dengan menggunakan rancangan cross-sectional yang merupakan rancangan penelitian dengan menggunakan pengukuran atau observasi ariable pada saat tertentu. Penelitian ini telah dilaksanakan diruang Hemodialisa RSUD Dr. M. Yunus Bengkulu pada tanggal 20 Juni - 20 Juli 2016. Sampel dalam penelitian ini adalah pasien hemodialisa yang sudah melakukan cuci darah diatas satu tahun yaitu sebanyak 50 orang. Instrument pengumpulan data berupa lembar angket dan lembar cheklist.Sebagian besar responden terapi hemodialisa diruang hemodialisa RSUD Dr. M. YUNUS Bengkulu yang memiliki mekanisme koping adaptif sebanyak 31 orang dari 50 orang responden. Hampir sebagian responden yang menjalani hemodialisis memiliki pengetahuan yang rendah yaitu sebanyak 21 orang dari 50 orang responden. Sebagian besar responden yang menjalani terapi hemodialisis berdasarkan tingkat pendidikan yaitu berpendidikan dasar (SD-SMP sederajat) sebanyak 21 orang dari 50 orang responden. Setengah dari responden yang menjalani terapi hemodialisis yaitu berusia dewasa madia 41-60 sebanyak 26 orang dari 50 orang responden. Responden yang menjalani terapi hemodialisis sebagian besar berjenis kelamin laki -laki yaitu sebanyak 29 orang dari 50 orang responden. Sebagian besar responden yang menjalani terapi hemodialisa memiliki harapan yang tinggi sebanyak sebanyak 25 orang dari 50 orang responden.
\end{abstract}

Kata kunci: Analisis Faktor, Hemodialisa, Mekanisme Koping

\begin{abstract}
Chronic Renal Failure (CRF)disease is a clinical state of progressive kidney damage and variable from various causes of diseases. From the data in some of the nephrology center in Indonesia estimated the incidence and prevalence of chronic kidney disease each ranging from 100-150 / 1 million inhabitants and 200-250 / 1 million population, but were diagnosed with
\end{abstract}


chronic renal failure on dialysis (Hemodialysis) only about 4000 to 5000 alone.This study aimed to determine the factors associated with the dominant coping mechanism on hemodialysis patients in hemodialysis unit of Dr. M. Yunus Hospital Bengkulu 2016.This study is an analytical research using cross-sectional design which use variable measurement or observation at a given moment. This study was conducted in Hemodialysis unit of Dr. M. Yunus Hospital Bengkulu on June 20 to July 20, 2016. The samples in this study were hemodialysis patients who had conducted dialysis over a year of 50 people. The instrument used were questionnaire and checklistsheets.Most respondents31 people from 50 respondents in hemodialysis unit of Dr. M. Yunus HospitalBengkulu adapted coping mechanisms. Almost all of the respondents 21 people had little knowledge. Most respondents primary who had education level (primary and junior equivalents) were 21 of 50 respondents. Half of the respondents aged 41-60 were26 people from 50 respondents. The respondents totally 29 people were largely male. Most respondents that had high hopes were 25 respondents.

\section{Keywords: Analysis Factor, Haemodialysis, Coping Mechanisms}

\section{PENDAHULUAN}

Penyakit gagal ginjal kronik (GGK) adalah keadaan klinis kerusakan ginjal yang progresif dan irreversibel yang berasal dari berbagai penyebab penyakit (Price \& Wilson 2005). Penyakit ini merupakan salah satu penyakit yang tidak menular yang telah menjadi masalah kesehatan masyarakat di dunia maupun negara kita dan dapat menyerang setiap orang baik pria maupun wanita tanpa memandang tingkat ekonomi (Kemenkes RI 2010). Menurut Baradero (2008), Penyakit gagal ginjal kronik ini terjadi apabila kedua ginjal sudah tidak mampu mempertahankan lingkungan dalam yang cocok untuk kelangsungan hidup.

Penderita gagal ginjal di Indonesia mencapai 70 ribu lebih. Dari data di beberapa pusat nefrologi di Indonesia diperkirakan insidens dan prevalensi penyakit ginjal kronik masing-masing berkisar 100-150/1 juta penduduk dan 200-250/1 juta penduduk, Namunyang terdeteksi menderita Gagal Ginjal Kronik yang menjalani cuci darah (Hemodialisa) hanya sekitar 4000 sampai 5000 saja (Yayasan Ginjal Diatrans Indonesia, 2012).

Menurut Smeltzer (2002) dalam Sari (2012) individu dengan hemodialisa jangka panjang sering merasa khawatir akan kondisi sakitnya yang tidak dapat diramalkan dan gangguan dalam kehidupannya.Mereka biasanya menghadapi masalah finansial, kesulitan mempertahankan pekerjaan, doronganseksual yang menghilang dan impotensi,depresi akibat sakit yang kronis dan ketakutan dan terhadap kematian.

Menurut PERNEFRI (2009) dalam Rahmadany (2015)di Indonesia penderita yang mengalami penyakitginjal kronik dan yang menjalani terapi hemodialisa mengalami peningkatan,dari survei yang dilakukan oleh Perhimpunan Nefrologi Indonesia terdapat 18 juta orang di Indonesia menderita penyakit ginjal kronik,data Indonesia Renal Regestry tahun 2007 jumlah pasien hemodialisa 2148penduduk sedangkan tahun 2008 jumlah pasien hemodialisa mengalamipeningkatan yaitu 2260 penduduk.

Gorman (2009) dalam Armiyati (2013) fenomena yang terjadi tidak semua penerimaan stres seperti yang diharapkan,bahkan tidak sedikit pasien yang mekanisme kopingnya belum adaptif. Penolakan yang ekstrim, ketidakpatuhan, agresif dan percobaan bunuh diri adalah beberapa respon maladaptif yang dapat terjadi. Penelitian oleh Zuhriastuti (2011) menunjukkan bahwa pasien CKD yang menjalani hemodialisis hanya $13,7 \%$ yang respon penerimaan stresnya berada dalam tahap menerima (acceptance). Sebagian besar respon penerimaan stres adalah angersebanyak 16 orang $(31,4 \%)$, bahkan ada denial sebanyak 14 orang $(27,5 \%)$ yang masihmenyangkal kondisinya.Penelitian juga menunjukkan bahwa sebagian besar 
mekanisme kopingpasien maladaptif yaitu sebesar $66,7 \%$.

Menurut Sudoyo (2006) dalam Rahmadany(2015) hemodialisa adalah mengeluarkan zat terlarut yang tidak diinginkanmelalui difusi dan hemofiltrasi untuk mengeluarkan air yang membawa serta zat terlarut yang tidak diinginkan.Menurut Smeltzer (2002) dalam Sari (2012) individu denganhemodialisa jangka panjang sering merasakhawatir akan kondisi sakitnya yang tidak dapat diramalkan dan gangguan dalam kehidupannya. Hemodialisa juga berdampak terhadap kehidupan sosial dan ekonomi penderita. Rumah Sakit Umum Daerah Dr. M. Yunus Bengkulu merupakan rumah sakit terbesar di Provinsi Bengkulu dan menjadi pusat rujukan, sehingga jumlah kunjungan rawat inap maupun rawat jalan lebih banyak. Menurut survey awal yang dilakukan penulis ditemukan kasus terjadinya hemodialisa pada tahun 2013 adalah sebanyak 1.200 pasien dengan 2.400 kunjungan, pada tahun 2014 terdapat 1.400 pasien dengan 2.820 kunjungan, pada tahun 2015 terdapat 1.600 pasien dengan 3.200 kunjungan (Medical Record RSMY, 2015)

\section{BAHAN DAN METODE}

Tehnik pengumpulan data yang digunakan dalam penelitian ini adalah dengan menggunakan data primer dan data sekunder. Data primer adalah data yang dikumpulkan melalui penyebaran kuisioner langsung pada responden di ruang Hemodialisa RSUD Dr. M. Yunus Bengkulu sedangkan data sekunder adalah data yang diperoleh dari buku register di ruang Hemodialisa RSUD Dr. M. Yunus Bengkulu

\section{HASIL}

Penelitian bertujuan untuk mengetahui faktor-faktor yang berhubungan dengan mekanisme koping pasien hemodialisa diruang hemodialisa RSUD Dr. M. Yunus Bengkulu tahun 2016. Metode penelitian yang digunakan dalam penelitian ini adalah penelitian analisis dengan metode crossectional. Populasi dalam penelitian ini adalah pasien yang menjalankan hemodialisa berjumlah 82 orang dengan sampel 50 orang. Dalam penelitian ini jenis data yang digunakan adalah data primer dan skunder. Data primer menggunakan angket yaitu tentang jenis kelamin, usia dan pendidikan. Sedangkan kuisioner yaitu tentang mekanisme koping, pengetahuan dan harapan pasien. Sedangkan data sekunder dilakukan dengan cara mengambil data melalui buku register diruang hemodialisa RSUD Dr. M. Yunus Bengkulu kemudian data yang diperoleh diolah dan dianalisa menggunakan analisis univariat dan bivariat.

Tabel 1. Distribusi frekuensi karakteristik responden diruang hemodialisa RSUD DR. M. YUNUS Bengkulu 2016

\begin{tabular}{ccc}
\hline $\begin{array}{c}\text { Karakteristik } \\
\text { Responden }\end{array}$ & N (Jumlah) & Persentase (\%) \\
\hline 1.Jenis Kelamin & & \\
\hline Laki-Laki & 29 & 58 \\
\hline Perempuan & 21 & 42 \\
\hline Total & 50 & 100 \\
\hline 2. Usia & & \\
\hline Awal Dewasa & 14 & 28 \\
\hline Dewasa Madya & 26 & 52 \\
\hline Dewasa Lanjut & 10 & 20 \\
\hline & & \\
\hline Total & 50 & 100 \\
\hline
\end{tabular}

Berdasarkan tabel 1 hasil analisa data didapat bahwa sebagian besar jenis kelamin yang menjalani terapi hemodialisi adalah berjenis kelamin laki-laki sebanyak 29 orang $58 \%$. Sedangkan responden yang menjalani terapi hemodialisi sebagian besar berusia dewasa madya 41-60 tahun sebanyak 26 orang $(52 \%)$.

Tabel 2. Distribusi frekuensi responden berdasarkan tingkat pendidikan responden menjalani terapi hemodialisis diruang hemodialisa RSUD DR. M. YUNUS Bengkulu 2016 


\begin{tabular}{ccc}
\hline Tingkat pendidikan & N (Jumlah) & Persentase (\%) \\
\hline Dasar & 21 & 42 \\
\hline Menengah & 19 & 38 \\
\hline Tinggi & 10 & 20 \\
\hline Total & 50 & 100
\end{tabular}

Berdasarkan tabel 2 Sebagian besar responden yang menjalani terapi hemodialisi berdasarkan tingkat pendidikan yaitu yang berpendidikan dasar (SD-SMP sederajat) sebanyak 21 orang $(42 \%)$.

Tabel 3 Distribusi frekuensi responden berdasarkan harapan responden menjalani terapi hemodialisis diruang hemodialisa RSUD DR. M. YUNUS Bengkulu 2016

\begin{tabular}{ccc}
\hline $\begin{array}{c}\text { Harapan akan self- } \\
\text { effiecacy }\end{array}$ & $\mathrm{N}$ (Jumlah) & Persentase (\%) \\
\hline Rendah & 20 & 40 \\
\hline Tinggi & 30 & 60 \\
\hline Total & 50 & 100 \\
\hline
\end{tabular}

Berdasarkan hasil analisa data di dapat bahwa dari 50 orang responden terbesar memiliki harapan akan self-effiecacy tinggi sebanyak 30 orang $(60 \%)$.

Tabel 4. Distribusi frekuensi responden berdasarkan tingkat pengetahuan menjalani terapi hemodialisis diruang hemodialisa RSUD DR. M. YUNUS Bengkulu 2016

\begin{tabular}{ccc}
\hline Tingkat Pengetahuan & $\mathrm{N}$ (Jumlah) & Persentase (\%) \\
\hline Rendah & 21 & 42 \\
\hline Sedang & 19 & 38 \\
\hline Tinggi & 10 & 20 \\
\hline Total & 50 & 100 \\
\hline
\end{tabular}

Berdasarkan tabel 4 hasil analisa data di dapat bahwa dari 50 orang responden yang menjalani terapi hemodialisi sebagian besar dengan tingkat pengetahuan rendah sebanyak 21 orang $(42 \%)$

Tabel 5. Distribusi frekuensi responden berdasarkan mekanisme koping diruang hemodialisa RSUD DR. M. YUNUS

\section{Bengkulu 2016}

\begin{tabular}{ccc}
\hline Mekanisme Koping & $\mathrm{N}$ (Jumlah) & Persentase (\%) \\
\hline Maladaptif & 19 & 38 \\
\hline Adaptif & 31 & 62 \\
\hline Total & 50 & 100 \\
\hline
\end{tabular}

Berdasarkan tabel 5 hasil analisa data di dapat bahwa sebagian besar yang menjalani terapi hemodialisi yaitu pasien memiliki mekanisme koping adaptif sebanyak 31 orang $(62 \%)$.

Tabel 6. Hubungan antara jenis kelamin yang menjalani terapi dengan mekanisme koping diruang hemodialisa RSUD Dr.M. YUNUS Bengkulu 2016

\begin{tabular}{ccccccc}
\hline $\begin{array}{c}\text { Jenis } \\
\text { Kelamin }\end{array}$ & \multicolumn{2}{c}{ Mekanisme Koping } & & \\
\cline { 1 - 5 } & \multicolumn{7}{c}{ Maladaptif } & \multicolumn{2}{c}{ Adaptif } & & \\
\hline & $\mathbf{F}$ & $\mathbf{\%}$ & $\mathbf{f}$ & $\mathbf{\%}$ & & \\
\hline Laki-laki & 17 & 58,6 & 12 & 41,4 & 29 & 100 \\
\hline Perempuan & 2 & 9,5 & 19 & 90,5 & 21 & 100 \\
\hline Total & $\mathbf{1 9}$ & $\mathbf{3 8 , 0}$ & $\mathbf{3 1}$ & $\mathbf{6 2 , 0}$ & $\mathbf{5 0}$ & $\mathbf{1 0 0}$ \\
\hline
\end{tabular}

Berdasarkan tabel 6 didapatkan hasil penelitian menunjukan bahwa dari 50 orang responden yang menjalani terapi hemodialisis terdapat 19 orang $(90,5 \%)$ yang memiliki mekanisme koping adaptif berjenis kelamin perempuan.

Tabel 7. Hubungan antara usia yang menjalani terapi dengan mekanisme koping diruang hemodialisa RSUD Dr. M. YUNUS Bengkulu 2016

\begin{tabular}{|c|c|c|c|c|c|c|}
\hline \multirow{3}{*}{ Usia } & \multicolumn{4}{|c|}{ Mekanisme Koping } & \multirow{3}{*}{ Jumlah } & \multirow{3}{*}{$\%$} \\
\hline & \multicolumn{2}{|c|}{ Maladaptif } & \multicolumn{2}{|c|}{ Adaptif } & & \\
\hline & $\mathbf{F}$ & $\%$ & f & $\%$ & & \\
\hline $\begin{array}{c}\text { Awal } \\
\text { Dewasa }\end{array}$ & 10 & 71,4 & 4 & 28,6 & 14 & 100 \\
\hline $\begin{array}{c}\text { Dewasa } \\
\text { Madya } \\
\text { Dewasa } \\
\text { Lanjut }\end{array}$ & $\begin{array}{l}7 \\
2\end{array}$ & $\begin{array}{c}26,9 \\
20\end{array}$ & $\begin{array}{l}9 \\
8\end{array}$ & $\begin{array}{c}73,1 \\
80\end{array}$ & $\begin{array}{l}26 \\
10\end{array}$ & $\begin{array}{l}100 \\
100\end{array}$ \\
\hline Total & 19 & 38 & 31 & 62 & 50 & 100 \\
\hline
\end{tabular}


Berdasarkan tabel 7 didapatkan hasil penelitian menunjukan bahwa dari 50 orang responden yang menjalani terapi hemodialisis terdapat 10 orang $(71,4 \%)$ dengan usia awal dewasa 18 - 40 tahun yang memiliki mekanisme koping maladaptif.

Tabel 8. Hubungan antara pendidikan yang menjalani terapi dengan mekanisme koping diruang hemodialisa RSUD Dr. $M$. YUNUS Bengkulu 2016

\begin{tabular}{ccccccc}
\hline \multirow{2}{*}{ Pendidikan } & \multicolumn{9}{c}{ Mekanisme Koping } & \multirow{2}{*}{ Jumlah } & \% \\
\cline { 2 - 6 } & Maladaptif & \multicolumn{3}{c}{ Adaptif } & & \\
\hline D & $\mathbf{F}$ & $\mathbf{f}$ & $\mathbf{\%}$ & & \\
\hline Denar & 12 & 57,1 & 9 & 42,9 & 21 & 100 \\
\hline Menengah & 6 & 31,6 & 13 & 68,4 & 19 & 100 \\
Tinggi & 1 & 10 & 9 & 90 & 10 & 100 \\
\hline Total & $\mathbf{1 9}$ & $\mathbf{3 8}$ & $\mathbf{3 1}$ & $\mathbf{6 2}$ & $\mathbf{5 0}$ & $\mathbf{1 0 0}$ \\
\hline
\end{tabular}

Berdasarkan tabel 8 Didapatkan hasil analisa data responden yang menjalani terapi hemodialisi yang memiliki mekanisme koping adaptif berpendidikan menengah sebanyak 13 orang $(68,4 \%)$.

Tabel 9. Hubungan antara harapan yang menjalani terapi dengan mekanisme koping diruang hemodialisa RSUD Dr. M. YUNUS Bengkulu 2016

\begin{tabular}{|c|c|c|c|c|c|c|}
\hline \multirow{3}{*}{ Harapan } & \multicolumn{4}{|c|}{ Mekanisme Koping } & \multirow{3}{*}{ Jumlah } & \multirow{3}{*}{$\%$} \\
\hline & \multicolumn{2}{|c|}{ Maladaptif } & \multicolumn{2}{|c|}{ Adaptif } & & \\
\hline & $\mathbf{F}$ & $\%$ & $\mathbf{f}$ & $\%$ & & \\
\hline Rendah & 14 & 70 & 6 & 30 & 20 & 100 \\
\hline Tinggi & 5 & 16,7 & 25 & 83,3 & 30 & 100 \\
\hline Total & 19 & 38 & 31 & 62 & 50 & 100 \\
\hline
\end{tabular}

Dari tabel 9 hasil analisa data responden yang menjalani terapi hemodialisi berdasarkan harapan yang memiliki mekanisme koping adaptif sebanyak tinggi sebanyak 25 orang $(83,3 \%)$.

Tabel 10. Hubungan antara pengetahuan yang menjalani terapi dengan mekanisme koping diruang hemodialisa RSUD Dr. M. YUNUS Bengkulu 2016

\begin{tabular}{ccccccc}
\hline \multirow{2}{*}{ Pengetahuan } & \multicolumn{9}{c}{ Mekanisme Koping } & \multirow{2}{*}{ Jumlah } & $\%$ \\
\cline { 2 - 6 } & Maladaptif & \multicolumn{2}{c}{ Adaptif } & & \\
\hline Rendah & 12 & 57,1 & 9 & 42,9 & 21 & 100 \\
\hline Sedang & 6 & 31,6 & 13 & 68,4 & 19 & 100 \\
Tinggi & 1 & 10 & 9 & 90 & 10 & 100 \\
\hline Total & $\mathbf{1 9}$ & $\mathbf{3 8}$ & $\mathbf{3 1}$ & $\mathbf{6 2}$ & $\mathbf{5 0}$ & $\mathbf{1 0 0}$ \\
\hline
\end{tabular}

Dari tabel 10 hasil analisa data responden yang menjalani terapi hemodialisi yang memiliki mekanisme koping adaptif berpengetahuan sedang sebanyak 13 orang $(68,4 \%)$

\section{PEMBAHASAN}

\section{Analisis Univariat}

a. Gambaran jenis kelamin yang menjalani terapi dengan mekanisme koping diruang hemodialisa RSUD DR. M. YUNUS Bengkulu 2016

Pada penelitian dari 50 orang responden sebagian besar laki-laki 29 orang menjalani terapi dengan mekanisme koping, Usia meningkatkan atau menurunkan kerentanan terhadap penyakit tertentu. Penelitan Yuliaw (2009) menyatakan, bahwa responden memiliki karakteristik individu yang baik hal ini bisa dilihat dari jenis kelamin, bahwa perempuan lebih banyak menderita penyakit gagal ginjal kronik, sedangkan laki-laki lebih rendah dan responden laki-laki mempunyai kualitas hidup lebih jelek dibandingkan perempuan, semakin lama menjalani terapi hemodialisa akan semakin rendah kualitas hidup penderita. Hasil penelitian diatas Penelitian juga menunjukkan perempuan secara keseluruhan lebih dapat menerima perawatan medis pada kesehatan mereka sedangkan laki-laki cenderung kurang dapat menerima intervensi perawatan kesehatan. perempuan seimbang.

b. Gambaran usia responden menjalani terapi dengan mekanisme koping diruang hemodialisa RSUD DR. M. YUNUS Bengkulu 2016 
Sebagian besar pada usia dewasa madya 41-60 tahun sebanyak 26 orang dari 50 responden yang menjalani terapi hemodialisis karena pada umumnya kualitas hidup menurun dengan meningkatnya umur. Penderita gagal ginjal kronik usia muda akan mempunyai kualitas hidup yang lebih baik oleh karena biasnya kondisi fisiknya yang lebih baik dibandingkan yang berusia tua. Penderita yang dalam usia produktif merasa terpacu untuk sembuh mengingat dia masih muda mempunyai harapan hidup yang lebih tinggi, sebagai tulang punggung keluarga, sementara yang tua menyerahkan keputusan pada keluarga atau anak-anaknya. Tidak sedikit dari mereka merasa sudah tua, capek hanya menunggu waktu, akibatnya mereka kurang motivasi dalam menjalani terapi hemodialisa. Usia juga erat kaitannya dengan prognose penyakit dan harapan hidup mereka yang berusia diatas 55 tahun kecenderungan untuk terjadiberbagai komplikasi yang memperberat fungsi ginjal sangat besar bila dibandingkan dengan yang berusia dibawah 40 tahun (Butar, 2008).

c. Gambaran tingkat pendidikan responden menjalani terapi dengan mekanisme koping diruang hemodialisa RSUD DR. M. YUNUS Bengkulu 2016.

Dari 50 orang responden yang menjalani terapi hemodialisi sebagian besar berpendidikan menengah sebanyak 19 orang karena itu mununjukan bahwa tingkat pendidikan merupakan tahapan pendidikan yang ditetapkan berdasarkan tingkat perkembangan peserta didik, tujuan yang akan dicapai dan kemauan yang dikembangkan. Tingkat pendidikan berpengaruh terhadap perubahan sikap dan perilaku hidup sehat. Tingkat pendidikan yang lebih tinggi akan memudahkan sesorang atau masyarakat untuk menyerap informasi dan mengimplementasikannya dalam perilaku dan gaya hidup sehari-hari, khususnya dalam hal kesehatan. Pendidikan formal membentuk nilai bagi seseorang terutama dalam menerima hal baru (Notoatmodjo 2003).
Yuliaw (2009) dalam penelitiannya mengatakan bahwa, pada penderita yang memiliki pendidikan lebih tinggi akan mempunyai pengetahuan yang lebih luas juga memungkinkan pasien itu dapat mengontrol dirinya dalam mengatasi masalah yang di hadapi, mempunyai rasa percaya diri yang tinggi, berpengalaman, dan mempunyai perkiraan yang tepat bagaimana mengatasi kejadian, mudah mengerti tentang apa yang dianjurkan oleh petugas kesehatan, serta dapat mengurangi kecemasan sehingga dapat membantu individu tersebut dalam membuat keputusan. Hasil penelitian ini didukung dengan teori dimana pengetahuan atau kognitif merupakan domain yang penting untuk terbentuknya tindakan, perilaku yang didasari pengetahuan akan lebih langgeng dari pada yang tidak didasari pengetahaun (Notoatmodjo, 2010).

\section{d. Gambaran harapan responden menjalani terapi dengan mekanisme koping diruang hemodialisa RSUD DR. M. YUNUS Bengkulu 2016.}

Berdasarkan hasil analisa data di dapat bahwa dari 50 orang responden yang menjalani terapi hemodialisi sebagian memiliki harapan akan self-effiecacy tinggi sebanyak 30 orang. Harapan akan selfefficacy berkenan dengan harapan kita terhadap kemampuan diri dalam mengatasi suatu masalah yang dihadapi, harapan terhadap kemampuan diri untuk menampilkan tingkah laku terampil, dan harapan terhadap kemampuan diri untuk dapat menghasilkan perubahan hidup yang positif ( Mutoharoh 2010).

\section{e. Gambaran pengetahuan responden menjalani terapi dengan mekanisme koping diruang hemodialisa RSUD DR. M. YUNUS Bengkulu 2016.}

Berdasarkan hasil analisa data di dapat bahwa dari 50 orang responden yang menjalani terapi hemodialisi dengan tingkat pengetahuan rendah sebanyak 21 orang 
karena pengetahuan merupakan hasil penginderaan manusia, atau hasil tahu seseorang terhadap objek melalui indra yang dimilikinya seperti mata, hidung, telinga, dan sebagainya. Pengetahuan merupakan faktor penting terbentuknya perilaku seseorang (Notoatmodjo 2003). Yuliaw (2009) dalam penelitiannya mengatakan bahwa, pada penderita yang memiliki pendidikan lebih tinggi akan mempunyai pengetahuan yang lebih luas juga memungkinkan pasien itu dapat mengontrol dirinya dalam mengatasi masalah yang di hadapi, mempunyai rasa percaya diri yang tinggi, berpengalaman, dan mempunyai perkiraan yang tepat bagaimana mengatasi kejadian, mudah mengerti tentang apa yang dianjurkan oleh petugas kesehatan, Namun hasil penelitian ini tidak sesuai dengan teori yang ada kemungkinan dikarenakan adanya perbedaan subjek penelitian dan pengalaman terdahulu dari masing-masing individu

\section{Analisis Bivariat}

a. Hubungan antara jenis kelamin yang menjalani terapi dengan mekanisme koping diruang hemodialisa RSUD DR. M. YUNUS Bengkulu 2016

Jenis kelamin merupakan identitas gender yang dimiliki seseorang. Jenis kelamin terbanyak pada responden yang menjalani terapi dengan mekanisme koping adalah lakilaki. Hasil uji statistik didapat ada hubungan yang signifikan antara jenis kelamin responden yang menjalani terapi hemodialisis dengan mekanisme koping. Dari hasil penelitian responden yang paling banyak menggunakan mekanisme koping adaptif adalah perempuan sebanyak 19 orangdibanding dengan responden laki-laki. secara keseluruhan perempuan lebih dapat menerima perawatan medis pada kesehatan mereka sedangkan laki-laki cenderung kurang dapat menerima intervensi perawatan kesehatan.

Menurut Friedman (2010) dalam Setiawati (2013), Pria dan wanita menggunakan strategi koping yang berbeda. Dari 80 strategi koping yang diteliti oleh Burr tahun 1994 pria dan wanita berbeda secara signifikan dalam menggunakan sepuluh strategi koping. Wanita menganggap lebih bermanfaat berkumpul bersama orang lain, berbagi kekhawatiran atau kesulitan mereka dengan teman dan kerabat, mengungkapkan perasaan dan emosi yang positif serta negatif secara terbuka, dan menghabiskan waktu guna mengembangkan diri dan hobi. Disisi lain, pria cenderung menggunakan strategi yang lebih menarik diri seperti mencoba menyimpan perasaannya, mencoba menjaga orang lain mengetahui seberapa buruk kejadianya, dan mengonsumsi alkohol lebih banyak.

Menurut Yin et.al. dalam Affandi (2009) ada perbedaan antara anak laki-laki dan perempuan dalam kontrol diri. Anak lakilaki lebih sering menunjukkan perilakuperilaku yang kita anggap sulit yaitu gembira berlebihan dan kadang-kadang melakukan kegiatan fisik yang agresif, menentang, menolak otoritas. Perempuan diberi penghargaan atas sensitivitas, kelembutan, dan perasaan kasih, sedangkan laki-laki didorong untuk menonjolkan emosinya, juga menyembunyikan sisi lembut mereka dan kebutuhan mereka akan kasih sayang serta kehangatan.

\section{b. Hubungan antara usia yang menjalani terapi dengan mekanisme koping diruang hemodialisa RSUD DR. M. YUNUS Bengkulu 2016}

responden yang menjalani terapi hemodialisis terdapat 10 orang dengan usia awal dewasa 18 - 40 tahun yang memiliki mekanisme koping maladaptif Penelitian mengenai mekanisme koping telah dilakukan Sanders (2010), dan hasilnya menunjukkan bahwa lansia menggunakan mekanisme koping berfokus emosi melalui berdo'a dalam mengatasi sakit pada penyakit kronis sel sabit,

Umur adalah rentang kehidupan yang diukur dengan tahun. Hurlock (2001) 
menyebutkan tahap perkembangan tersebut meliputi periode prenatal, bayi, masa dewasa awal, dewasa madya, dan lanjut usia. dikatakan masa awal dewasa adalah usia 18 tahun sampai 40 tahun, dewasa Madya adalah 41 sampai 60 tahun, dewasa lanjut $>60$ tahun. Proses menua (aging) adalah prosesalami yang dihadapi oleh manusia.Manusia akan mengalami perubahan melaluitahap-tahap perkembangan seiring dengan berjalannya waktu. Stickle dan Onedera (2006) melaporkan bahwa sekitar $80 \%$ dari lansia memiliki minimal satu kondisi penyakit kronis sehingga akan menambah penderitaan emosionalnya.

c. Hubungan antara pendidikan yang menjalani terapi dengan mekanisme koping diruang hemodialisa RSUD DR. M. YUNUS Bengkulu 2016

Dari hasil analisa data responden yang menjalani terapi hemodialisi yang memiliki mekanisme koping adaptif berpendidikan menengah sebanyak 13 orang. Pendidikan adalah upaya persuasi atau pembelajaran kepada masyarakat agar masyarakat mau melakukan tindakan-tindakan (praktik) untuk memelihara (mengatasi masalah-masalah), dan meningkatkan kesehatannya. (Notoatmodjo, 2005). Pada penelitian ini diketahui adanya hubungan antara tingkat pendidikan menjalani terapi hemodialisis dengan mekanisme koping.

Hasil penelitian ini sejalan dengan teori dari Notoatmodjo (2005) yang menyatakan bahwa tingkat pendidikan individu memberikan kesempatan yang lebih banyak terhadap diterimanya pengetahuan baru termasuk informasi kesehatan. Dalam hal ini diharapkan dengan adanya informasi yang diterima individu mampu menentukan langkah yang harus ia ambil untuk menyelesaikan masalah yang sedang dihadapinya.

d. Hubungan antara harapan yang menjalani terapi dengan mekanisme koping diruang hemodialisa RSUD DR.

\section{YUNUS Bengkulu 2016}

Dari hasil analisa data responden yang menjalani terapi hemodialisi berdasarkan harapan yang memiliki mekanisme koping adaptif sebanyak tinggi sebanyak 25 orang $(83,3 \%)$. Apabila individu tidak mempunyai kemampuan untuk menanggulangi tantangan - tantangan penuh stres yang dihadapi dalam hidup, maka individu tersebut akan merasa semakin cemas bila menghadapi tantangan tantangan itu (Bandura dkk, 1985).

Individu dengan self-efficacy tinggi meyakini bahwa kerja keras untuk menghadapi tantangan hidup, sementara rendanya self-efficacy kemungkinan besar akan memperlemah bahkan menghentikan usaha seseorang. Jika seseorang percaya bahwa mereka mampu melakukan sesuatu secara efektif dengan stresor yang ada, mereka tidak akan terganggu. Tapi jika mereka percaya mereka tidak mampu mengendalikan keadaan, mereka akan terkena distres, individu tidak mampu menggunakan koping secara maksimal dan melihat dunia sebagai sesuatu yang mengancam. Beberapa literatur menegaskan bahwa self-efficacy memiliki pengaruh pada sikap (Bandura, 1997).

\section{e. Hubungan antara pengetahuan yang menjalani terapi dengan mekanisme koping diruang hemodialisa RSUD DR. M. YUNUS Bengkulu 2016}

Dari hasil analisa data responden yang menjalani terapi hemodialisi berdasarkan pengetahuan yang memiliki mekanisme koping adaptif sedang sebanyak sebanyak 13 orang Meskipun pengetahuan merupakan salah satu faktor yang diduga dapat mempengaruhi perilaku seseorang dalam bertindak atau melakukan suatu hal pada penelitian ini tidak sepenuhnya mekanisme koping yang digunakan oleh klien responden yang menjalani terapi hemodialisis didahului oleh pengetahuan yang baik. Ketidak seimbangan antara koping individu dengan banyaknya informasi yang tersedia dapat 
menghambat kesembuhan. Pada suatu penelitian, pasien-pasien penyakit jantung pengguna koping represif (mengandalkan penyangkalan) yang menerima informasi lengkap tentang keadaan mereka menunjukkan tingkat komplikasi medis yang lebih tinggi daripada pasien yang menggunakan koping represif tapi tidak menerima informasi lengkap tentang keadaan mereka (Shaw, 1985 dalam Nevid, 2005).

Dengan hasil penelitian yang menunjukkan belum ada cukup bukti untuk menyatakan hubungan antara pengetahuan dengan mekanisme koping yang digunakan oleh pasien yang menjalani terapi hemodialisis. Menurut peneliti kemungkinan disebabkan oleh banyaknya informasi yang diterima dan harus dipahami oleh pasien terkait penyakit dalam rangka untuk memelihara kesehatan.

\section{KESIMPULAN}

Berdasarkan hasil penelitian yang telah dilakukan di ruang Hemodialisa RSUD Dr. M. YUNUS Bengkulu, maka dapat disimpulkan sebagai berikut:

1. Sebagian besar responden terapi hemodialisia memiliki mekanisme koping adaptif sebanyak 31 orang.

2. Hampir sebagian responden memiliki pengetahuan yang rendah yaitu sebanyak 21 orang.

3. Sebagian besar responden berdasarkan tingkat pendidikan yaitu berpendidikan dasar (SD-SMP sederajat) sebanyak 21 orang.

4. Setengah dari respondenyaitu berusia dewasa madia 41-60 sebanyak 26 orang.

5. Responden yang menjalani terapi hemodialisis sebagian besar berjenis kelamin laki -laki yaitu sebanyak 29 orang.

6. Sebagian besar responden memiliki harapan yang tinggi sebanyak sebanyak 25 orang.

\section{SARAN}

1. Bagi Akademik

Hasil penelitian ini dapat menambah materi pendidikan kesehatan dan dapat menambah referensi untuk perpustakaan serta mata kuliah Penelitian ini dapat menambah kajian ilmu pengetahuan mengenai mekanisme koping yang digunakan oleh responden yang menjalani terapi hemodialisis.

2. Bagi penelitian selanjutnya

Dari hasil penelitian ini, diketahui bahwa yang terbukti berhubungan secara signifikan dengan mekanisme koping yaitu jenis kelamin dan harapan Oleh karena itu, penulis menyarankan dilakukan analisa multivariat untuk melihat faktor yang paling dominan dan mempengaruhi kontribusinya antara variabel independen terhadap dependen.

\section{Bagi Rumah Sakit}

Dapat memberikan masukan serta informasi tambahan bagi Ruang Hemodialisa RSUD Dr. M. Yunus Bengkulu untuk program di masa datang sehingga dapat menentukan upaya apa yang dapat dilakukan dan meningkatkan penyuluhan tentang Hubungan Analisis Faktor yang Berhubungan dengan Mekanisme Koping Pasien Hemodialisa Diruang Hemodialisa RSUD Dr. M. Yunus.

\section{Bagi Responden}

Hasil penelitian ini dapat menambah pengetahuan dan wawasan responden mekanisme koping pasien hemodialisa.

\section{DAFTAR PUSTAKA}

Armiyati Y, Rahayu DA (2013). FaktorYang Berkorelasi Terhadap Mekanisme Koping Pasien Ckd Yang Menjalani Hemodialisis Di Rsud Kota Semarang. Fakultas Ilmu Keperawatan dan Kesehatan UMS. Semarang

Baradero, M, Dayrit, M.W \& Siswandi, Y 
(2008).Seri asuhan keperawatan klien gangguan ginjal, EGC, Jakarta

Bandura, A. (1985). Explorations in selfefficacy. In S. Sukemune (Ed.),Advances in social learning theory. Tokyo: Kaneko-shoho

Bandura, A. (1997). Self-efficacy and health behaviour. In A. Baum, S. Newman, J. Wienman, R. West, \& C. McManus (Eds.),Cambridge handbook of psychology, health and medicine(pp. 160-162). Cambridge: Cambridge University Press.

Friedman, M.M, Bowden, V.R,\& Jones, E.G (2010).Buku ajar keperawatan keluarga : riset, teori, \& praktik, edk 5, EGC, Jakarta.

Hurlock E.B. (2001). Psikologi Perkembangan edisi kelima: Suatu Pendekatan Sepanjang Rentang Kehidupan. (Terjemahan olehIstiwidayanti \& Sujarwo). Jakarta: PT.Gelora Aksara Pratama.

Kemenkes RI (2010).Petunjuk teknis pengendalian penyakit ginjal kronik, Bakti Husada, Jakarta.

Medical Record RSMY. 2015. Data Register Pasien Hemodialisa. Profil Kesehatan RSMY Bengkulu

Mutoharoh (2010). Faktor-Faktor Yang Berhubungan Dengan Mekanisme Koping Klien Gagal Ginjal Kronik Yang Menjalani Terapi Hemodialisis Di Rumah Sakit Umum Pusat (Rsup) Fatmawati Tahun 2009. Prodi Keperawatan FKIK UIN Syarif Hidayatullah. Jakarta

Nevid, J.S., Rathus, S.A. \& Greene, B. (2005). Psikologi Abnormal, Edisi kelima, Jilid 2. Jakarta: Penerbit Erlangga.

Notoatmodjo, S(2003). Pendidikan dan Perilaku Kesehatan. Jakarta: Rineka Cipta

Notoatmodjo, S(2010). Metodologi Penelitian Kesehatan. Jakarta: Rineka Cipta

Price, S. A. \& Wilson, L. M (1995). Patofisiologi: Konsep klinis prosesproses penyakit, Edisi 4, EGC, Jakarta.
Rahmadany A (2015). Perbedaan Mekanisme Koping Pada Pasien Gagal Ginjal Kronik Laki-Laki Dan Perempuan Yang Menjalani Hemodialisa Di Rs Pku Muhammadiyah Gombong. STIKES Muhammadiyah Gombong. Gombong Sanders K.A., Labott S.M., Molokie R., Shelby S.R., \& Desimone J. (2010) Pain, Coping and Health Care Utilization in Younger and Older Adults with Sickle Cell Disease. Journal Health Psychology,15(1), 131-7

Sari Y (2012). Hubungan Tingkat Stres Dan Strategi Koping Pada Pasien Yang Menjalani Terapi Hemodialisa. Universitas Riau. RIAU

Setiyawati L (2013).Perbedaan Mekanisme Koping pada Pasien Gagal Ginjal Kronik Laki-laki dan Perempuan dalam Menjalani Hemodialisis di RSUD Kraton Kabupaten Pekalongan. STIKES Muhammadiyah Pekajangan. Pekalongan

Smeltzer, Suzanna C (2001). Buku Ajar Keperawatan Medikal - Bedah, Brunner \&Suddarth; Ed.8 Vol.1 (terjemahan). Jakarta; EGC.

Stickle F., \& Onedera J.D (2006). Depression in older adults (geriatric depression). Article Adultspan Journal

Yayasan Ginjal Diatrans Indonesia (2012). Emosi Labil pada Pasien Gagal Ginjalee, Dialife, dilihat 15 Januari $2013<$ www.statmyweb.com/s/yayasankesehatan-ginjal.html $>$

Yuliaw, Anny(2009). Hubungan Karakteristik Individu dengan Kualitas Hidup Dimensi Fisik pasien Gagal Ginjal Kronik di RS Dr. Kariadi Semarang.Diakses daridigilib.unimus.ac.id/files/disk1/106/ jtpunimus-gdl-annyyuliaw-5289-2bab2.pdf pada tanggal 29 Agustus 2013 